\title{
Transphobia and gender identity: social representations of trans women from Brazil and Colombia
}

\author{
Transfobia e identidade de gênero: \\ representações sociais de mulheres trans do Brasil e Colômbia
}

María del Mar Sánchez-Fuentes (https://orcid.org/0000-0003-3657-4981) ${ }^{1,2}$
Ludgleydson Fernandes de Araújo (https://orcid.org/0000-0003-4486-7565) ${ }^{3}$
Sandra Milena Parra-Barrera (https://orcid.org/0000-0002-0056-4389) ${ }^{4}$
Érika Rhayane Sousa Fontes (https://orcid.org/0000-0001-5755-9700) ${ }^{3}$
José Victor de Oliveira Santos (https://orcid.org/0000-0002-6661-2873) ${ }^{3}$
Nieves Moyano (https://orcid.org/0000-0002-5416-9464) ${ }^{5}$

${ }^{1}$ Faculty of Human and Social Sciences, Department of Social Sciences, University de La Costa. Calle 58 \# 55 - 66. Barranquilla Colombia. marsanchez@unizar.es ${ }^{2}$ Faculty of Social and Human Sciences, University of Zaragoza. Teruel Spain.

${ }^{3}$ Universidade Federal do Piauí. Teresina PI Brasil. ${ }^{4}$ Fundación plan de Investigación, Derechos Humanos y Educación Sexual (FIDHES).

Barranquilla Colombia.

${ }^{5}$ Faculty of Humanities and Education Sciences, University of Jaén. Jaén Spain.

\begin{abstract}
The present research aimed to identify and discuss the social representations of trans women related to gender identity and transphobia in Brazil and Colombia. In this study participated 43 Trans women, 22 from Brazil, aged between 18 and 55 years $(M=29.09, S D=8.53)$ and 21 from Colombia, aged between 21 and 41 years $(M=28.19, S D=7.63)$. This study adopted a qualitative approach in which semi-structured interviews were used. The data were analyzed by the Iramuteq software, which identified the social representations in classes. The results showed what the participants understood about transphobia and how they regarded their experiences with this gender identity. The participants presented negative social representations, aiming at their personal experiences related to their social context. Themes related to violence, discrimination, prejudice, denial of rights and family support emerged from both the Brazilian and Colombian sample. Implications for Tran's quality of life are discussed.

Key words Transphobia, Identity, Tran's women, Social representations
\end{abstract}

Resumo A presente pesquisa teve como objetivo identificar e discutir as representações sociais de mulheres trans relacionadas à identidade de gênero e transfobia no Brasil e na Colômbia. Neste estudo participaram 43 mulheres trans, 22 do Brasil, com idade entre 18 e 55 anos ( $M=29,09$, $D P=8,53)$ e 21 da Colômbia, com idade entre 21 e 41 anos $(M=28,19, D P=7,63)$. Este estudo adotou uma abordagem qualitativa na qual foram utilizadas entrevistas semiestruturadas. Os dados foram analisados pelo software Iramuteq, que identificou as representações sociais. Os resultados mostraram o que os participantes entenderam sobre transfobia e como eles encararam suas experiências com essa identidade de gênero. Os participantes apresentaram representações sociais negativas, visando suas experiências pessoais relacionadas ao seu contexto social. Temas relacionados à violência, discriminação, preconceito, negação de direitos e apoio familiar emergiram da amostra brasileira e colombiana. Espera-se que este estudo possa contribuir para compreensão deste fenômeno biopsicossocial.

Palavras-chave Transfobia, Identidade, Mulheres Trans, Representações sociais 


\section{Introduction}

It is broadly known that, in the contemporary world, there is a huge variety of gender identities, and, among them, the transsexuality. All of them are part of the human sexuality types, which are beyond male and female. Within this contemporary context, it is noticed, in a highly evidenced way, a huge amount of prejudice and violence against female cross-dressers and transsexual women. Because of that, it is important to highlight the fact that this issue stems from an old social construction ${ }^{1}$. According to Lacerda et al. ${ }^{2}$, the LGBT intolerance was strengthened by Christian dogmas, and from them, normal and abnormal practices started to be defined. This constituted the sexual prejudice that is taken to the Trans context, for people who identified with that identity are also subjected to social exclusion, once they do not fit in to the heteronormativity rules imposed by society.

Within this perspective, Silva and Santos ${ }^{3}$ claim that the subjects who identify as being trans carry with them other belonging groups, as subjects considered abnormal, deviating and eccentric; they are part of the population that are under a vulnerability situation, due to prejudice and discrimination. Radkowsky and Siegel ${ }^{4}$ consider that the social isolation, caused by exclusion and prejudice, may make the individuals have low self-esteem, being exposed to loneliness feelings, depression, and can even try to suicide because of the dissatisfaction with their own living.

Regarding gender identity, Trans people face, in their life course, a lot of struggle to access basic human rights; besides that, they are victims of violent intolerant attitudes in society ${ }^{5}$. This way, the accessibility difficulties that Trans individuals face due to their subjective identities frame losses in the scope of schooling, work, leisure, culture and even of public security; from that situation, arises a scenario in which those people have only a minimum access to citizenship ${ }^{6}$. Oliveira et al. ${ }^{7}$, in their considerations about prejudice, claims that, even when the intentions in favor of diversity inclusion are good, i.e., when the cognitive and affective purposes generated from prejudice are not noticed, there is a tendency to repeat the exclusion practices, affecting the fundamentals of the openness to current thoughts and to liberty, even concerning sexual and gender ones. This is very common contemporarily, by means of inclusion forms inserted in the policy that, in a certain way, instead of including the subject, categorizes and classifies them as if they were different from the others.
On the studies of social representations, Moscovici $^{8}$ describes the existence of two domains of thoughts that make use of reason in modern society: the one of science and the one of common sense. This way, these two are related to elaborate the social representations, and from this affinity, they make the individual reflect on their way of acting in their daily living by means of dialogue. That idea implies that each subject carries, in their existence, conceptions that are shared within the collective ideas that constitute the subjects, rehabilitating the common sense, turning it essential for the construction of the human and their sociologic and psychological integrality. Before that, it can be seen how much this interaction among the subjects makes the ideas modify or configure along the years and build new social spaces.

However, in current days, although Trans people have gained some social space because of movements in favor of gender equality and despite the achievements for the use of a social name, equality is still a factor that is far from Brazilian reality. In Brazil, there are very high indexes of violence against trans people, in fact, it occupies the first place in the world ranking of countries where the most murders take place against the trans group'. The violence is justified by religious positioning, heteronormative ideologies, among others, which harm those people's rights, causing huge suffering, which is reflected in their lives, hampering their insertion in social spaces and even taking off their right of travel ${ }^{10}$. In addition, it is one of the Latin American countries that is experiencing a setback in terms of legislation, as the National LGBTI Council (Decree 9,883/2019) was recently eliminated and the government's agenda is contrary to inclusive education $^{11}$, which has a direct impact on LGBTI people. Brazilian Trans people have reported to suffer disrespect toward the adopted name, trans/travestiphobia in healthcare services among others, that imped them from egatitarian and universal access to an unified health system ${ }^{12}$. In Colombia, the evolution of the rights concerning the LGBT public is remarkable; for Trans people, the legal support is progressing, and adapting to the public's specificities. This fact will possibly contribute to the reduction of expressions of prejudice ${ }^{13}$. However, religious beliefs and heteronormative ideologies also predominate. Likewise, Colombia ranks third among the Latin American countries where most of the murders against trans people take place ${ }^{9}$ and where the armed conflict has had negative consequences on sexual minorities ${ }^{14}$. 
Because of the great index of prejudice with Trans people, it is necessary to carry out studies on this theme, for it is still a recent topic, and there are few studies in the area that emphasize the importance of breaking taboos on the topic and discuss about the prejudice from the current society, in both Brazil and Colombia. Transphobia is the prejudice directed at people whose gender identity or gender expression does not conform to social norms and expectations. It contributes to the marginalization of trans people ${ }^{15}$. Social representations are a way of social knowledge, of interpreting and thinking about everyday reality, that is, they are collective in nature and allude to the reality shared by a group ${ }^{16,17}$. Thus, the importance of studying social representations about gender identity and transphobia lies in making visible the shared beliefs and attitudes of the same group (trans women). Social representations can induce processes of social classification and these processes are essential to delimit shared beliefs. Therefore, the main goal of this research is to identify and discussing the social representations of Trans women in relation to gender identity and transphobia in Brazil and in Colombia.

\section{Methods}

\section{Participants}

In the Brazilian study, 22 Trans people participated; they were between 18 and 55 years old, $\mathrm{M}=29.09$ ( $\mathrm{SD}=8.53)$. In relation to their marital status, $68.2 \%$ was single, $4.5 \%$ was married, $18.2 \%$ was in a stable union and $9.1 \%$ was in a different marital status. Regarding schooling, $4.5 \%$ of the participants has not finished elementary school; $18,2 \%$ has completed only elementary school; $27.3 \%$ is composed of secondary school dropouts; $13.6 \%$ has studied until finishing secondary school; $22.7 \%$ has started a graduation, without having finished it; and 9.1\% has completed a post-graduation course.

Other 21 Trans people, Colombian, participated of the research. They aged from 21 and 41 years old, $\mathrm{M}=28.19$ ( $\mathrm{SD}=7.63$ ). Regarding their marital status, $76.1 \%$ is single and $23.8 \%$ is married. In relation to their education, $9.5 \%$ of them have only completed elementary school; $38.09 \%$ has completed secondary school; $4.7 \%$ has started, but not finished, graduation and $23.8 \%$ has completed a graduation course.

The criteria for including the participants in the study were being 18 years old or older and be- ing a Tran's woman. That is, people who at birth and because of their genitals were considered as men, however at present they feel women, and that they have adopted only gender roles (transgender) or have resorted to hormonal treatment and/or surgery (transsexuals).

\section{Instruments}

We used a semi-structured interview. It had the following questions: "What do you understand by transphobia?" and "How do you see your living experience considering your gender identity?" Moreover, we employed a sociodemographic questionnaire. We gathered information on participants' gender, age, marital status, education, and nationality.

\section{Procedure}

The sample was recruited using a non-random sampling procedure, snowballing due to the characteristics of the sample, in the main cities of Brazil (São Paulo, Rio de Janeiro and Brasília) and Colombia (Bogotá, Medellín and Barranquilla). Participants were contacted by email and phone between April and June 2019. Those who were interested in participating read the informed consent, which explained the general objective of the study, and signed the consent. The semi-structured interview was conducted in person (BLINDED headquarters) or by phone, and the approximate time was 30 minutes. The confidential character of the participation in the research was highlighted to the participants, with the assurance that the results would only be presented in scientific events or scientific journals. This study was approved by the Ethics Committee on Human Research of the University of BLINDED. All participants were volunteers and received no compensation for their participation.

\section{Statistical analysis}

The questions of the semi-structured interview were analyzed by means of a free software, Iramuteq, which allows to carry out statistical analysis of text data and of tables of individuals/ word. The analysis of similarity is based upon the theory of graphs, which, in turn, allows to identify the incidences among words, bringing a result of connection among the words.

Camargo and Justo ${ }^{18}$ indicate that in the analysis with Iramuteq, the material is structured into: corpus, which is the set of written material 
to be analyzed; a text referring to the set of texts that makes an analysis corpus, appropriate to the analysis carried out by means of Descending Hierarchical Classification. That set must be a collection of the texts centralized on a specific topic; excerpts of texts are fragments of written material with three lines of extension, formed by Iramuteq itself.

\section{Results}

The social representations of the Trans women participating of the research were analyzed separately, i.e., two textual corpus were used, one from Brazil and another from Colombia. That was done in order to allow the identification of the closeness and differences of the social representations between the two countries.

\section{Transphobia and gender identity among Brazilian Trans women}

In this analysis, regarding the question about what the participants understood by transphobia and how they saw their living experiences considering their identities resulted in corpus 1 . Different ideas can be found, but most participants provided negative information on the way that they are seen by society and the daily struggles. The corpus is composed of Unities of Initial Context (UCIs) and 59 Unities of Complementary Context (UCEs), in which 54 were retained (91.52), in a total of occurrences equivalent to 690 , with an average 25.5 words in each UCE.

In dendrogram 1 (Figure 1), six classes are recorded; they can be defined as: Violence of Society, Discriminated identity, Judgment and lack of knowledge of rights, Prejudice and fight for social space, Denial of Rights and Family Support, corresponding, respectively, to classes 1, 2, 3, 4, 5 and 6 . The following indications are presented: the UCEs per class, the descriptive variable representing the sample, the average frequency of each word and the value of the chi-square.

The first division of corpus 1 originated two sub-corpus, the first one composed of class 6 and the second one composed of classes 1, 2, 3, 4 and 5 . In the first sub-corpus, class 6 , named as Family support, represents $18.52 \%$ of the UCEs classified in their content. The living experiences of the Trans women are represented by a perspective of struggling related to the identities and to the necessity of having family support so the experiences can be strengthened. Transphobia is seen as violence and discrimination against Trans identities. Such discourses may be seen below:

It's not easy to be Trans, for many judge without knowing, but it's not a choice. It would be worse to be something we are not, hiding the person we really are would be much worse. But it's important to have support from the family, which is the basis for everything. It gives me strength to be who I really am and was born to be (Participant 3, single, 24 years).

The participant demonstrates that it is a struggle to face her identity; however, in her speech, she shows a fulfillment feeling when she mentions being Trans, and emphasizes the importance of the family within this process as a necessity to face the difficulties:

I consider it is good, once I am aware of my orientation without the need to offend or to judge the ones who don't have the same view as mine. I respect each person's orientation, like I expect mine to be respected. Transphobia is negative attitudes adopted by someone who believes to have the right to interfere with the others' sexual orientation. Those are people who feed anger feelings, intentional or not, towards transgender people and cross-dressers (Participant 11, married, 28 years).

In the social representations, respect seen as something important for the construction of identities and the dissatisfaction with transphobia are issues that can be identified, for it can be inferred that this attitude internalizes and externalizes a negative feeling that affects people who identify themselves as Trans people.

This construction of identity mentioned by the participant leads to the idea that she can only see a healthy and positive possibility a situation in which others do not interfere with their orientation. Besides that, there is a feeling of inequality, which places the participant in an inferior position in relation to the cisgender heterosexual orientation. All of those issues frequent nourish a society that transfers hate and violence against those people.

In the second sub-corpus, composed of classes 1, 2, 3, 4 and 5 there was a sub-division in which classes 1, 2, 3 and 4 were placed as opposite to class 5 . There was also a third division, placing classes 1, 2 and 3 in opposition to 4, and classes 2 and 3 were in opposition to class 1 .

Class 1, Violence of society, with 8 UCEs and $14.81 \%$ of the total classified, presented, as content, the fear of suffering violence because of their identities. This class is related to classes 2 and 3 (Discriminated identity and Judgment and lack of knowledge of rights), which had the same 

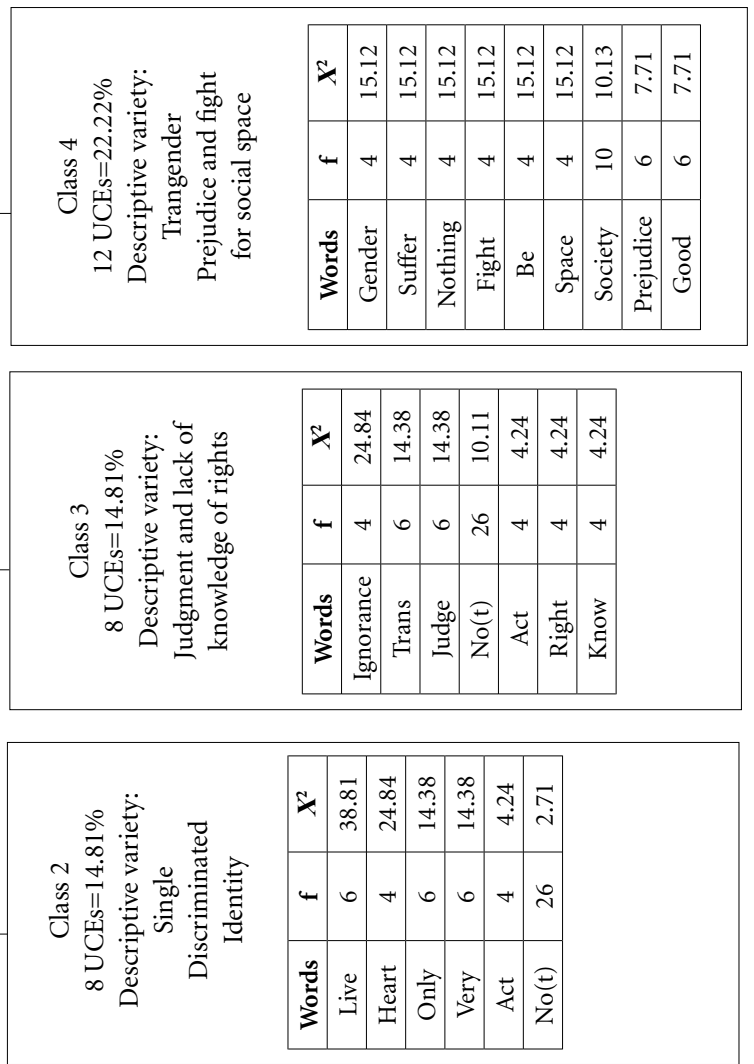

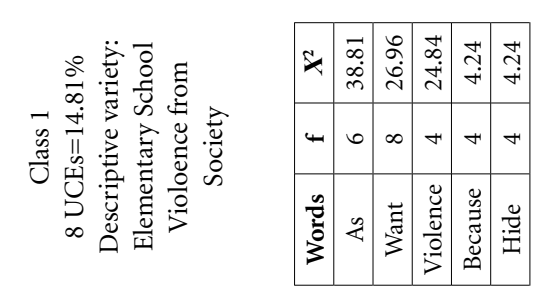

\begin{tabular}{|c|c|c|c|c|c|c|}
\hline 今े & $\approx \begin{array}{l}\infty \\
\cdots \\
0 \\
0\end{array}$ & : & $\mid \begin{array}{l}\overrightarrow{0} \\
\dot{\sigma}\end{array}$ & 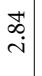 & & 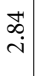 \\
\hline 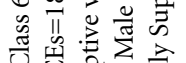 & $-\infty$ & $\infty$ & + & + & & + \\
\hline ดั & \begin{tabular}{l|l}
0 \\
\multirow{2}{*}{}
\end{tabular} & 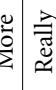 & $\mid \begin{array}{c}\hat{\vec{z}} \\
\text { ज्ञ } \\
\end{array}$ & $\begin{array}{l}3 \\
\vdots \\
\vdots \\
\end{array}$ & & $\bar{\nabla}$ \\
\hline
\end{tabular}


quantity of UCEs and contents regarding the perception of the insecurity of the social space surrounded by discrimination (class 2). In class 3 , the content concerns the challenges that the cross-dressers face to have rights within society. This way, the speeches below affirm the results of the classes presented:

Honestly, it is hard, not only for me, but to all $L G B T$ people, for the discrimination is very present in the society we live in. It's sad to see so many people dying and to know that I can be another dead one. I just wanted to live in peace and live tranquil$l y$, far from human cruelty. Transphobia is an act from people who just have hate in their hearts and pick on and hurt those who want to be free (Participant 15, single, 31 years).

The participant describes the difficulty faced by embracing all the vulnerability groups, for the discrimination is always present, affecting them in a tragic way. She also demonstrates some anguish when she claims not having peace in her experiences, saying that she wanted to live her liberty without any risk:

A stupid act that hurts people's souls. A challenge, for people don't know how to respect our rights (Participant 2, in a stable union, 31 ).

In this description, the participant feels that people do not have knowledge about her identity, and that this fact affects the integrity of Trans women. She finds her living challenging, because her rights denied.

It is important to highlight, in the social representations of the participants, the presence of a perception of inequality and injustice that permeate the life of people who identify with the Trans identity, for they demonstrate the desire of being free and having the same rights as the others. Moreover, they wish to be able to enjoy their personal desires without the risk of suffering violence or even having their right to live taken away, once they demonstrate a constant fear of the future because society has shown to be inconstant before the high index of killed LGBT people.

Class 4, named Prejudice and fight for social space, represents $22.22 \%$ of the UCEs classified. It showed the difficulties for those women to have their own space, due to the prejudice from the cisnormative society. This claim can be noticed in the following excerpt:

To sum up, I can say that there's hate for people who transgress cisnormativity. A daily struggle for space in society (Participant 1, 39 years).

The participant affirms that the transphobia can be practiced by the social view of "power", which determines the heteronormativity as the only possibility to be accepted and well seen. Besides that, she feels that being Trans is a challenge for she is not accepted in the spaces that she wishes to be in.

Finally, class 5, named Denial of rights, which has $14.81 \%$ of the UCEs, presented the lack of recognition of the identity and the denial of the rights that they need so they can go through social spaces. In the participants' speeches, this affirmation is seen:

Living is fighting and resisting, although I'm not as vulnerable as other girls. Transphobia is the lack of recognition of the gender identity of trans people (Participant 16, single, 28 years).

I'd like to be seen as a normal person in society, just that!!! Because if there weren't prejudice, I'd have the opportunity to make my dreams come true, like I've always wanted. There are many kinds of violence against cross-dressers (Participant 21, single, 18 years).

Participant 16 believes that, although she is in a vulnerable situation, there are people who are at a higher risk, i.e., besides being Trans, there are other characteristics that are not accepted by society and that puts them at a more significant risk. She believes that transphobia is a fact that occurs with the lack of recognition of Trans as an identity.

\section{Transphobia and gender identity among Colombian Trans women}

The second corpus was composed of 21 UCIs, resulting in 62 UCEs; a number of 45 of them was retained, making $72.58 \%$ of the total. As for the occurrences, there was a total of 2090 , with 33.7 words in average in the UCEs. The corpus originated five classes (Figure 2), in which the first group originated classes 2 and 3 , and, in the second group, class 5 , followed by another group with classes 1 and 4 .

In dendrogram 2 (Figure 2), five classes were registered, and defined as: Knowledge in Childhood, Social Acceptance, Family Acceptance, Hate from society, Intolerance and little respect, corresponding respectively to classes 5, 4, 1,2 and 3 . The UCEs were indicated per class and descriptive variable representative of the sample, the average frequency of each word and the chi-square value.

Class 5, named as Knowledge in childhood, had a representation of $20 \%$ of the UCEs classified according to their content. Facing the representation of Trans people, a desire for the change of social conceptions that are expressed in a neg- 


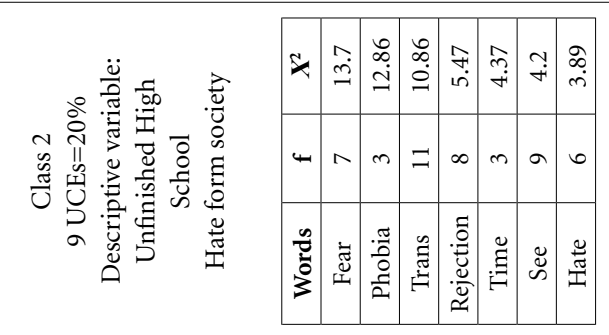

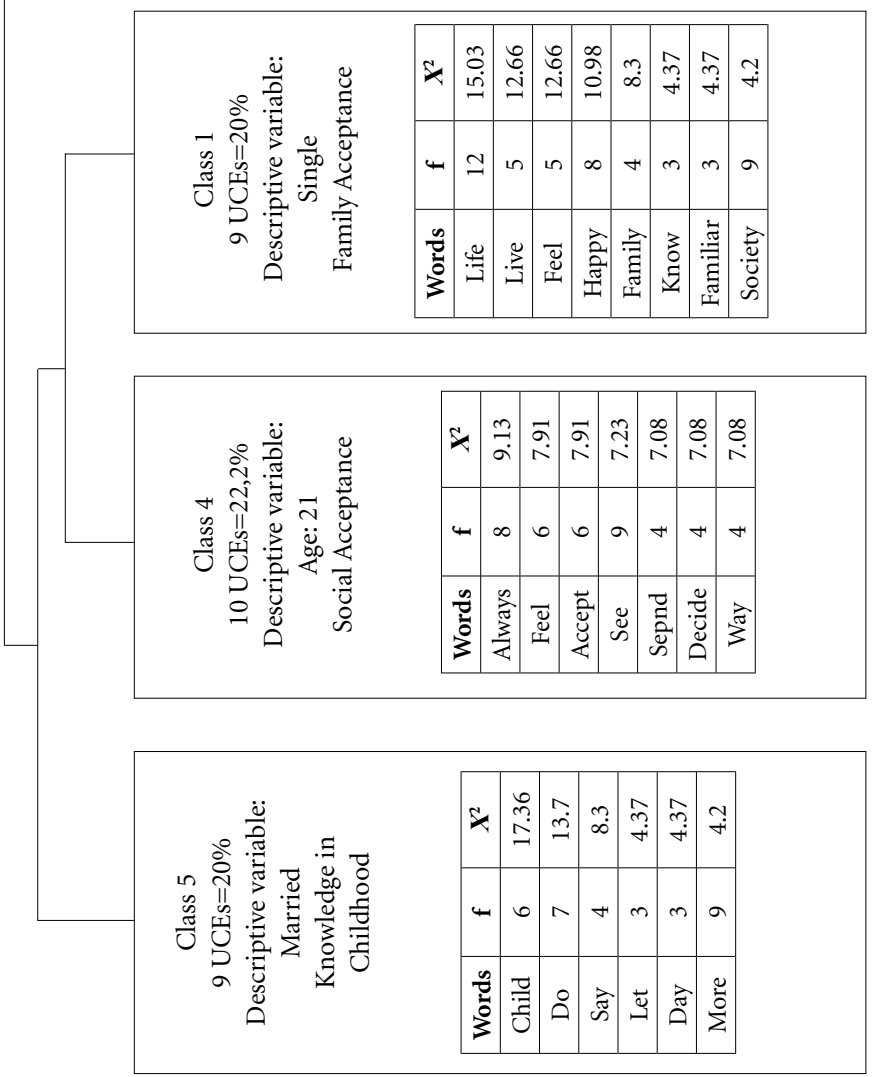


ative way is noticed, emphasizing the importance to provide knowledge about gender and sexuality since childhood, so there is freedom for each person to decide on their orientation. In the following speech, this conception can be noticed:

It could be changed, improved, solved at the beginning, by teaching children early about gender and sexuality, leaving machismo behind and giving children the liberty to do and choose things that make them feel good, not deny them, for social reasons, they should not act in a certain way or wear clothes that they shouldn't, for example, you can't like pink because it's an only girls' color or force girls to dress in a certain way, more feminine, or acting more femininely, because it's like this that a girl should behave (Participant 5, married, 23 years).

Class 4, named Social Acceptance, was formed of $22.22 \%$ of the UCEs in its content. In the speech of the participants, it is possible to identify the prejudice and the anger that society emits, interfering, in a significant way, with the person's integration in social environment and with their progress development to conquer social space:

The hate, the dislike for transsexual people coming from people who feel they have authority and the right of judging people like me is very unfortunate, because this influences a lot on the growth of people like me (Participant 5, married, 23 years).

Class 1, named Family Acceptance had 20\% of the classified UCEs in its content. In this class, it was noticed that the experience of having the gender identity exposed had, consequently, the non-acceptance from the family, for family understood that she was doing something wrong. In the following speech, one of the participants says how difficult it was to face the prejudice that she went through her living in the social, religious and mainly family environments:

My experience, when noticing that I didn't want to grow up with the gender that was attributed to me when was born was terrible, for I didn't know what to do or what to say, and my family didn't do anything or just punished me and mocked me when I wanted to express that. I grew up thinking it was bad, and I didn't want anything bad for my life. I was also within religious processes and felt worse than a roach, I had to fight against a lot of prejudice from myself. When I was able to overcome some of the prejudice, I decided to step forward and now I feel free and a bit more silent; although having to deal with other people's prejudice, is tiring, and there are times when they don't want to listen, I think a cultural change is important and we should leave the taboo behind (Participant 16, single, 25 years).

Class 2, named Hate from Society, is composed of $20 \%$ of the UCEs classified in their content. In this class, the dissatisfaction of the participants in relation to the ignorance of people who express prejudice is exposed. On the other hand, despite of the difficulties that they face, they feel satisfied by the freedom they had concerning their gender identity, which is an achievement. In the speech below, this claim can be noticed:

It's stupidity, and a misused word, because phobia is fear, and we don't kill each other for fear, we are killed by hate. My life experience is unique, because although I've had to painfully sacrifice many things for being who I really love to be, it was worth, for the freedom and the autonomy I have on my life and my body is a luxury for few people (Participant 21, single, 30 years).

The last class, class 3, was named Intolerance and little respect; it represented $17.78 \%$ of the UCEs in its content. This class evidences the anguish that the participants had due to the discrimination they have been through in their lives, since their childhood until adulthood. It also shows the fear of loneliness and the necessity to "create" a personality to please people. Besides that, it shows the criticism of the Christian ideas, which contribute for people to see transsexuality as something sinful. In the speech below, the participant demonstrates this affirmation:

I grew up feeling very fearful, it was like having a delirium of being persecuted, because every time I went out, groups of children would chase me to say ugly things, spit on me or hit me, and adult men only looked at me in disgust and said ugly things. Within the family environment, I was treated with some distance by my mother's family; this affected me, because even in the place where I lived, I couldn't express who I really was. I had to create a certain "personality" due to the fear I had in my mind, that they'd notice who I really was and expel me from home. Of course, since I was 5 years old I've known that, either if my family expelled me form home or if I decided to live my life the way that made me happy, I would turn into a prostitute. Because that was what they have always implied. That is what you see on TV or on the streets. Whenever I was at a mass, the Father said bad things about people with gender identity and a not normal sexuality, within a binary, as if they were monsters, demons, freaks, which made me feel guilty. Fear. In addition, a lot of sadness. I never had friends during um childhood. Therefore, during adolescence, I felt the "necessity" to accept 
friends. Moreover, I started acting the way I should, an easy-going and funny person so people accepted me and loved me. I have always been sad, have always thought about suicide (Participant 5, married, 23 years).

\section{Discussion}

In relation to the social representations of the Trans women, we observed that the data obtained in the semi-structured interviews represented the transphobia and the gender identity as a coping process in various aspects. That was due to the exclusion, marginalization, denial of social rights, lack of job opportunities, physical and psychic violence and even the endangered right to live that those women suffer, results similar to those reported in previous studies ${ }^{19}$.

This study confirms the difficulties faced by the Trans people. In this perspective, it co-opts the point of view of Jesus ${ }^{20}$ who considers that there is a resistance to accept transsexuals and cross-dressers in the family, in the work field and in the society, among other fields that impede the insertion of those groups of people. Souza ${ }^{21}$ affirms the same point of view, claiming that there is a daily struggle for those people to enter the formal work market. Moreover, the prejudice and the low education level are impediments that cross those people's ways, hampering the achievement of their aims.

The social representations highlighted by the participants show negativity in the process of their coping, for society does not have the necessary support to overcome the barriers that affect them. Besides this lack, a great part of society reinforces this suffering with transphobic attitudes, which are hidden behind cultural values, religion and determinism, factors that feed the discriminative behavior and the prejudice within society. Previous research in Brazil, indicates that hegemonic social representations still support stereotyped masculine and feminine roles ${ }^{22}$, in which other forms of gender identity are not included.

The results showed a relation between Brazil and Colombia regarding the transphobia that reaches that population and hampers the living of those subjects. There are interconnected issues, such as: lack of family acceptance, social prejudice, lack of information, rejection, fear, feeling accepted, desire to be respected and feel free to live without being afraid. Those relations found show the importance for themes approaching transphobia to have more social visibility and that the generations must have more information so that the prejudice can be finally extinguished.

An author who also has this same thought concerning the society influence on prejudice ${ }^{2}$ describes the prejudice as a historical-culture construction, highlighting that, from Christianism, the homoerotic was considered sinful, for not being in accordance to what was considered the word of God. Besides that, medicine also had its influence when it defined, in the 19th century, that the homosexuality was a biological disorder. To complete those ideas, psychoanalysis and psychology classified it as perversion. This way, it is suggested that the prejudice becomes a consequence of the determination that led the subjects to have conceptions that produce transphobia in society.

Most institutions are not prepared to deal with the Trans public ${ }^{23}$. However, the school context is the one that causes more difficulties for the development of a Trans person ${ }^{7}$. The social representations noticed in this study confirm that the internalization of the prejudice and the fear shared by trans people, as other researches, either in $\mathrm{Brazil}^{3}$ or in Colombia ${ }^{24}$.

Lasso $^{24}$ claims that the diagnosis in gender dysphoria is the first step for the assurance of rights. In Brazil, the public policies have been evolving; some states have health centers for hormonal treatment and some facility for name changing. However, there are not fundamentals in the country as a whole ${ }^{25}$. In Colombia, the situation is similar, in a way that it is necessary to seek for the public health system for hormonal treatment and surgeries. The juridical and parliamentary recognition in the national scope will possibly bring improvements to that population - not only in relation to sexual adequacy, but also regarding citizenship ${ }^{26}$. Also, this qualitative study with Brazilian and Colombian population will help to establish evaluation protocols. According to previous research ${ }^{27}$, it is important to establish standardized evaluation protocols and with at least two evaluators.

The present study approached the social representations of Trans women about transphobia and gender identity. Regarding transphobia, the social representations are presented in a homogeneous way, embracing negative meanings, so the participants of the research relate their representations to the experience lived, placing exclusion and prejudice as aggravating factors in this process. Furthermore, an important aspect is that transphobia and the situation of vulnerability experienced by trans people may vary according to cultural factors, not only due to religion ${ }^{2}$, but 
also to other aspects such as ethnicity, according to what was indicated by one of the participants and as previous studies have shown ${ }^{28,29}$. Because of that, the prejudice is a very recurrent problem in the living of the participants of the study. It could be observed that there is a negative representation of their lives, based upon fear, pain, impotence, anguish, disillusion and lack of hope for the future. This could be noticed from the data obtained in Brazil and in Colombia, showing the high index that reaches a huge part of those countries. However, the participants in the present research did not report on issues more related to personal gender identity, such as the shift from the male to the female model. For example, trans people who have a negative self-perception of their voice (ie, very masculine voice) report a worse quality of life, that is, negative self-perception about their own gender identity may be related to transphobia, as well as with the decrease in the well-being of trans people $e^{30,31}$. These results are relevant in order to establish evaluation and psychological care protocols for this population. In this sense, there are numerous studies that show that living with social vulnerability is associated with psychological disorders and suicide attempts ${ }^{32-36}$, substance abuse ${ }^{32,37}$ higher risk of sexually transmitted infections ${ }^{38}$ (all of which also reinforces the stigmatization ${ }^{33}$ and decreases well-being ${ }^{39}$ ). In addition, research with sexual minorities are scarce ${ }^{40}$.

Finally, it is required to mention the limitations from this study. The main limitation is that findings cannot be generalized to the general Trans population. Therefore, it is recommended for future studies to use mixed methods, which allow obtaining all the information that the qualitative method allows, but also include questionnaires and statistical analyzes to obtain more information. Also, in the present study only Trans women were recruited. Therefore, further studies are necessary, for we notice a necessity to enlarge the focus on this population and search within the psychological science, strategies to include them to the society, making it more just and egalitarian. However, this research is a scientific advance in the study of sexual minorities in Latin American countries such as Brazil and Colombia.

\section{Collaborations}

All the authors collaboratively conceived the present study in the following roles: Conceptualization: MM Sánchez-Fuentes, LF Araújo, SM Parra-Barrera, ÉRS Fontes, JVO Santos and N Moyano. Methodology: MM Sánchez-Fuentes, LF Araújo and N Moyano. Analisys and results: MM Sánchez-Fuentes, LF Araújo, ÉRS Fontes, JVO Santos. Writing and original draft preparation: MM Sánchez-Fuentes, LF Araújo, SM Parra-Barrera, ÉRS Fontes, JVO Santos and N Moyano. Writing, review and editing: MM Sánchez-Fuentes, LF Araújo, SM Parra-Barrera, ÉRS Fontes, JVO Santos and N Moyano. All authors have read and agreed to the published version of the manuscript. 


\section{References}

1. Cunha AM, Coêlho TF. Trans-subjetividade na blogosfera: uma abordagem sobre gênero e escrita de si. Passagens 2016; 6(2):165-183.

2. Lacerda M, Pereira C, Camino L. Um estudo sobre as formas de preconceito contra homossexuais na perspectiva das representações sociais. Psico Reflex Crit 2002; 15(1):165-178.

3. Silva BB, Santos ES. Apoio e suporte social na identidade social de travestis, transexuais e transgêneros. Rev SPAGESP 2014; 15(2):27-44.

4. Radkowsky M, Siegel LJ. The gay adolescent: stressors, adaptations, and psychosocial interventions. Clin Psychol Rev 1997; 17(2):191-216.

5. Melo TCL, Cavalcante ADC, Araújo CAR, Almeida Neto T, Ferreira LCO. Despatologização das identidades trans-a saída para uma sociedade mais igualitária. Cad Grad-Cien Hum Soc-Unit-Alagoas 2017; 3(3):6984.

6. Almeida GS. Reflexões iniciais sobre o processo transexualizador no SUS a partir de uma experiência de atendimento. In: Arila M, Lapa TS, Pisaneschi TC, organizadores. Transexualidade, travestilidade e direito à saúde. São Paulo: Oficina Editorial; 2010. p. 117-148.

7. Oliveira CP, Dal Rovere C, Oliveira DAS. Nome social: uma luta por direitos. Rev Thêma Scientia 2017; 6(2E):132-143.

8. Moscovici S. Representações Sociais - Investigações em psicologia social. Rio de Janeiro: Vozes; 2017.

9. Association of Transvestites and Transsexuals of Brazil. Report on murders and violence against transvestites and transsexuals in 2018. Brazil: ANTRA; 2019.

10. Oliveira PVP. Liberdade de gênero e sexualidade: o papel da educação na construção da identidade. Rev Communitas 2017; 1(1):233-246.

11. Colombia Diversa. Prejudice knows no borders. Lesbian, gay, bisexual, trans and intersex killings in Latin American and Caribbean countries 2014-2019 [Internet]. Colombia; 2019 [acessado 13 out 2018]. Disponível em: https://colombiadiversa.org/colombiadiversa2016/wpcontent/uploads/2019/08/Informe_Prejuicios_web.pdf.

12. Rocon PC, Rodrigues A, Zamboni J, Pedrini MD. Difficulties experienced by trans people in accessing the unified Health system. Cien Saude Colet 2016; 21(8):2517-2526.

13. Cardinali DC. Direitos LGBT e cortes constitucionais latino-americanas: uma análise da jurisprudência da Colômbia, Peru, Chile e Brasil. RFD UERJ 2017; 31:25-68.

14. Colombia Diversa. Live under suspicion [Internet]. Colombia; 2015 [acessado 13 out 2018]. Disponível em: http://www.colombiadiversa.org/conflictoarmado-lgbt/.

15. United Nations Development Programme. Chapter 2. Stigma, discrimination, violence \& human rights. In: Implementing comprehensive HIV and STI programmes with transgender people. New York: UNDP; 2016.

16. Jovchelovitch S. Knowledge in Context: Representations, community and culture. London: Routledge; 2007.

17. Moscovici A. Social collectivities. In: Hulsen M. Essays in Honor of Elias Canetti. Londres: André Deutsch; 1987. p. 42-59.
18. Camargo BV, Justo AM. IRAMUTEQ: um software gratuito para análise de dados textuais. Temas Psicol 2013; 21(2):513-518.

19. Reisner SL, Poteat T, Keatley J, Cabral M, Mothopeng T, Dunham E, Holland CE, Max R, Baral SD. Global health burden and needs of transgender populations: A review. Lancet 2016; 388(10042):412-436.

20. Jesus JG. Transfobia crime de ódio: Assassinato de pessoas transgênero como genocidio. Hist Agora 2013 16:101-123.

21. Souza H. Os desafíos do trabalho na vida cotidiana de mulheres transexuais [tese]. Campinas: PUC-Campinas; 2012.

22. Nascimento IRD, Neves ALMD, Rodrigues PF, Teixeira E. Social representations of masculinities in the short film "Aids, choose your form of prevention". Cien Saude Colet 2020; 25(3):879-890.

23. Santos JVO, Carlos KPT, Araújo LF, Negreiros F. Compreendendo a velhice LGBT: uma revisão da literature. In: Araújo LF, Carvalho CMRG, organizadores. Envelhecimento e Práticas Gerontológicas. Curitiba, Teresina: Editora CRV/EDUFPI; 2017. p. 81-96.

24. Lasso RA. Transexualidad y servicios de salud utilizados para transitar por sexos-géneros. Rev CES Psicol 2014; 7(2):108-125.

25. Bento B. Nome social para pessoas trans: cidadania precária e gambiarra legal. Rev Sem Depart Progr PosGrad Sociol UFSCar 2014; 4(1):165-182.

26. Carvajal-Muñoz PM. El reconocimiento de derechos a la comunidad LGBTI. Jurídicas CUC 2013; 9(1):123141.

27. Jones BA, Brewin N, Richards C, Van Eijk M, Stephenson-Allen A, Arcelus J. Investigating the outcome of the initial assessment at a national transgender health service: Time to review the process? Int J Transgenderism 2017; 18(4):427-432.

28. Nemoto T, Sausa LA, Operario D, Keatley, J. Need for HIV/AIDS education and intervention for MTF transgenders: responding to the challenge. J Homosex 2006; 51(1):183-201.

29. Jefferson K, Neilands TB, Sevelius J. Transgender women of color: discrimination and depression symptoms. Ethn Inequal Health Soc Care 2013; 6(4):121.

30. Schmidt JG, Goulart BN, Dorfman ME, Kuhl G, Paniagua LM. Voice challenge in transgender women: trans women self-perception of voice handicap as compared to gender perception of naïve listeners. Rev CEFAC 2018; 20(1):79-86.

31. Dornelas R, Guedes-Granzotti R, Silva A, Batista de Jesus AK, da Silva, K. Quality of life and voice: the vocal self-perception of transgender people. Audiol Commun Res 2020; 25(e2196):1-5.

32. Benotsch EG, Zimmerman R, Cathers L, McNulty S, Pierce J, Heck T, Perrin PB, Snipes D. Non-medical use of prescription drugs, polysubstance use, and mental health in transgender adults. Drug Alcohol Depen 2013; 132(1-2):391-394.

33. Bockting WO, Miner MH, Swinburne RE, Hamilton A, Coleman E. Stigma, mental health, and resilience in an online sample of the US transgender population. Am J Public Health 2013; 103(5):943-951. 
34. Budge SL, Adelson JL, Howard KA. Anxiety and depression in transgender individuals: the roles of transition status, loss, social support, and coping. J Consult Clin Psychol 2013; 81(3):545-557.

35. Clements-Nolle K, Marx R, Katz M. Attempted suicide among transgender persons: The influence of gender-based discrimination and victimization. $\mathrm{J} \mathrm{Ho}$ mosexuality 2006; 51(3):53-69.

36. Haas AP, Eliason M, Mays VM, Mathy RM, Cochran SD, D'Augelli AR, Silverman MM, Fisher PW, Hughes T, Rosario M, Russell ST, Malley E, Reed J, Litts DA, Haller E, Sell RL, Remafedi G, Bradford J, Beautrais AL, Brown GK, Diamond GM, Friedman MS, Garofalo R, Turner MS, Hollibaugh A, Clayton PJ. Suicide and suicide risk in lesbian, gay, bisexual, and transgender populations: Review and recommendations. $J$ Homosex 2011; 58(1):10-51.

37. Glynn TR, van den Berg JJ. A systematic review of interventions to reduce problematic substance use among transgender individuals: A call to action. Transgend Health 2017; 2(1):45-59.

38. Poteat T, Wirtz AL, Radix A, Borquez A, Silva-Santisteban A, Deutsch MB, Khan SI, Winter S, Operario D. HIV risk and preventive interventions in transgender women sex workers. Lancet 2015; 385(9964):274-286.

39. Warren JC, Smalley KB, Barefoot KN. Psychological well-being among transgender and gender queer individuals. Int J Transgenderism 2016; 17(3-4):114-123.

40. Calvillo C, Sánchez-Fuentes MM, Sierra JC. Revisión sistemática sobre la satisfacción sexual en parejas del mismo sexo. Rev Iberoam Psicol Salud 2018; 9(2):115136.

Article submitted 30/03/2020

Approved 22/09/2020

Final version submitted 24/09/2020

Chief editors: Romeu Gomes, Antônio Augusto Moura da Silva 